\title{
A Policy Agenda for Changing our Relationship with Consumption
}

Dr lain R. Black*

Heriot Watt University School of Management and Languages, Heriot-Watt University, Edinburgh, Scotland, EH14 4AS, Tel: +44 1313803 I.R.Black@HW.ac.uk

Professor Deirdre Shaw

Adam Smith Business School, University of Glasgow, Gilbert Scott Building, Glasgow G12 8QQ.01413305411. Deirdre.Shaw@glasgow.ac.uk

Dr Katherine Trebeck

Oxfam GB, c/- Oxfam Scotland. 10 Bothwell Street, Glasgow G2 6LU. Tel: 0141285 8850. KTrebeck@oxfam.org.uk

${ }^{*}$ Corresponding author

Accepted refereed manuscript of: Black IR, Shaw D \& Trebeck K (2017) A policy agenda for changing our relationship with consumption, Journal of Cleaner Production, 154, pp. 12-15. DOI: $10.1016 / j$.jclepro.2017.03.182

(C) 2017, Elsevier. Licensed under the Creative Commons Attribution-NonCommercialNoDerivatives 4.0 International http://creativecommons.org/licenses/by-nc-nd/4.0/ 


\begin{abstract}
In this Government Initiatives contribution, we present policy recommendations made available to the Scottish Government on how to change Scottish consumers' relationships with material goods and so contribute to its greenhouse gas emissions targets. Rather than focusing on the individual actions of consumers, we discuss how the underlying neoliberal political narrative must be addressed as it creates the conditions in which invidious materialism can occur. We then propose an alternative conceptualization of marketing that would harness marketing tools and concepts to help build connections between people and stimulate demand for pro-environmental, prosocial, consumption. This function stands in contrast to marketing acting in a way that contributes to the fragmentation of society and degradation of our planet. A series of controls on marketing are then outlined, which seek to facilitate changes to current dominant consumption narratives including using material input labelling as a mechanism to restrict unethical marketing practices. Overall, these ideas represent a more interventionist perspective, but one that we deem necessary when considered against the scale of the task now facing humanity in avoiding catastrophic climate change.
\end{abstract}

\title{
Keywords:
}

Sustainable Consumption, Materialism, Controlling Marketing, Narratives, advertising to children

\section{Acknowledgements:}

Dr John Desmond, Ben Wray, Joshua Graham, and Common Weal think-tank 


\section{Introduction}

The discipline of Marketing has been rightfully criticized for stimulating novel, repeated, and wasteful consumption, a fundamental cause of anthropogenic climate change and the unsustainable exploitation of the earth's resources (Stocker, 2014). Marketing is 'the management process responsible for identifying, anticipating and satisfying customer requirements profitably' (Chartered Institute of Marketing, 2016) Yet as currently practiced, it often sanctions and spurs the expansion of consumption and does so in a way that can develop an invidious materialism (Ger and Belk, 1999; Page, 1992). Invidious materialism imbues social interactions where spending, status and group memberships become defined by what, where, how and with whom you consume (Shukla, 2008), rather than on intrinsic relationships, the skills one possesses or what one does. In addition to the environmental damage to which such materialism contributes (Black and Cherrier, 2010), research has for some time noted that increasing consumption after a certain point does not necessarily increase our levels of happiness (Csikszentmihalyi, 2000) and instead contributes to decreases in social and personal wellbeing (Badot and Cova, 2008; Shultz and Holbrook, 1999).

Typically, individuals are seen as possessing the agency to respond to the product offerings constructed by marketers and actively choose what, where and how to consume (Ellen et al., 1991; Leary et al., 2014; Vicente-Molina et al., 2013). Following this logic, policy interventions aimed at addressing the link between consumer consumption and climate change (rather than sustainability) predominantly focus on persuading the consumer to consume differently (Prothero et al., 2010).

In this Government Initiatives contribution, we highlight policy recommendations available to the Scottish Government (Black et al., 2015) on how it may help to change its citizens' relationship with material goods and contribute to it attaining its stringent greenhouse gas emissions targets (Scottish Government, 2016). We argue that government policy must also address the underlying neoliberal economic narrative that shapes the conditions in which excessive consumer demand is repeatedly stimulated, rather than relying on individuals to act counter to the dominant narrative and systemic structures. Public policy must also more actively control marketing practices in order to 
rebalance the public's need for goods and services with our planet's ability to provide these sustainably.

We outline a policy agenda that proposes changes to the language and policy priorities of government that can redefine this narrative to one where environmental harmony, society building, greater equality, and participation - rather than passive consumption - are the fundamental goals. Having suggested changes to some of the conditions under which marketing is practiced, we propose using Badot et al.'s (1993) alternative conceptualization of this discipline, drawing on their description of as marketing as societing. This definition appropriates marketing tools and concepts so that rather than contributing to the fragmentation of society and degradation of our planet marketing is cast as a facilitating activity that builds connections between us and stimulates demand for pro-environmental and prosocial consumption. To aid these areas, and in support of calls from other authors, controls on marketing practices are also outlined (Harris et al., 2009; Schor, 2004). Overall, these interventions are capable of stimulating demand for sustainable forms of consumption by helping to redefine societal and individual notions of ownership, bolstering broader definitions of prosperity (Jackson, 2011). Together, we recommend this more interventionist approach as a way of balancing appropriate consumer needs with our planet and society's ability to satisfy them sustainably.

\section{Consumption Narrative}

Narratives are connected stories that effectively transfer and share cultural meaning; narratives help us construct our understanding of reality or 'how things work' (Bruner, 1991) Narratives occur over time, have a sequence, are about people acting in a particular setting and are based on events that are ethically important. The preeminence of a neoliberal political and economic narrative across the United Kingdom, the United States of America, and elsewhere has existed for over three decades (Centeno and Cohen, 2012). It is based on valorisation of private rather than public control of the supply of goods and services as a mechanism for increasing wealth (equated with welfare) and is supported by promoting the rights of the individual over 
the collective (Black et al., 2015; Centeno and Cohen, 2012; Hardin, 2009). Crucially, it states that what you possess demonstrates your success and who you are (Black et al., 2015). The market supports this individualism by providing the symbolic resources required to construct and reconstruct self-identity through our possessions and experiences (Arnould and Thompson, 2005). A necessary condition for high levels of material consumption is the availability of credit so that the desire to consume is supported with the ability to do so. Hence, through light touch regulation, banks are able to make consumer credit widely available through personal loans, credit cards, equity release schemes and more recently, capital from pensions (Ivanova, 2011). In addition, planning laws are redesigned to promote out-of-town shopping centers where the desire and financial means to consume are matched with the availability of goods, albeit often at the expense of the city centers in which people used to live.

Across society, this narrative replicated and extended itself, based on the story that in the 1970s wasteful, inefficient state-run organizations were holding society back and needed to be replaced by vigorous and effective private ownership. Over time, this logic was extended from electricity, water, and sewerage services to include banks, health services and prisons. The narrative purports that living wages, environmental protection, and health and safety protections for workers are costs that drive up prices for the consumer and the market should decide such issues.

Government's support and implement narratives in two main ways: the first by enacting enabling legislation, and the second by expressing the doctrine through speeches, interviews, press releases and public service announcements/advertising (Harvey, 2007). In the case of the neoliberal narrative, Brown (1997) goes as far as to suggest that its effect has been so profound as to have reversed strongly held societal positions. For example, greed has moved from being a "deadly sin" to a lauded trait and high levels of personal debt have become normalized rather than being a source of shame.

We contend here that before governments can seek to change unsustainable consumption behaviors and practices, they must first address the neoliberal narrative of 'how things work' in our society since it is this narrative that drives individualistic consumption and invidious materialism. We contend that if government legislation and 
communication supported the importance of collective ownership and participation as a symbolic resource, then marketers would reframe their activities in accordance with the 'new' landscape which in turn would help reduce overconsumption.

\section{Changing the Language of Government}

As an important initial step, changes are required to the language used by governments and governance. The language used in speeches, press releases, tenders or specific social marketing communications frames government intentions and frames their vision of how a country should develop. Table 1 sets out some suggestions for specific changes that might slow replication of the neoliberal narrative.

Table 1: Proposed changes to the language of government

\begin{tabular}{|ll|}
\hline PROMOTE & REPLACE \\
\hline We & I \\
Citizens & Consumers \\
Shared ownership & Private \\
Social & Privatization \\
Prosperity & Individual \\
Sharing & Profit \\
Empowerment & Exploitation \\
Needs & Establishment \\
Interdependence & Wants \\
Enough & Competition \\
Slow & More \\
Rental & Convenience \\
Empathy & Individual ownership \\
Circular & Greed \\
Participation & Linear \\
\hline
\end{tabular}


As the language of government changes, the work of Abelson et al. (1968) on cognitive consistency (where we attempt to match what we think with what we do), suggests it becomes easier to restrict the marketing of personally and socially damaging products whilst also simultaneously promoting and allocating funds to pro-social and proenvironmental activities.

\section{From Manipulator to Facilitator}

Whilst acknowledging the negative aspects of marketing, we also view the techniques and skills of marketing as capable of encouraging a different relationship with consumption and consumer goods. In short, the issue lies not with marketing as a discipline per se, but in how it is currently practiced and to what end. In exploring how different forms of consumption can lead to marketing being conceptualized in a facilitative role, Kate Soper's work on alternative hedonism is offered here. This work calls for a reconsideration of the dominant understanding of the 'good life' and points to a means to reconnect humans with the pleasures of consuming differently (Soper, 2007; Soper, 2008; Soper, 2009). Distinct from messages to limit consumption (Connolly and Prothero, 2003), alternative hedonism seeks a refocusing to the intrinsic pleasures of consuming differently, such as slowing down, contemplation, relaxation, sharing, and doing (Soper, 2008). It calls for individuals and groups to look beyond quick and easy consumer fixes, to acknowledge the limits of the market in terms of fulfilling personal pleasure and collective wellbeing (Soper, 2013) and to consider the civic dimension of the label 'consumer' (Soper, 2005).

Whilst it is not suggested that such changes will be without perceived sacrifices in terms of currently prevailing notions of pleasure and convenience, it argues that gains will outweigh losses both individually and collectively. A contrast between this approach and more common current market offerings can be seen where solutions to a lack of time are offered (for example, pre-packaged food, cars), but in doing so inexpensive pleasures are forgone (such as preparing and sharing a meal and walking) (Soper, 2008). In other examples of this alternative form of consuming, public spaces given 
over to gardens can invite reconnection with nature and relaxation without marketbased purchasing, so encouraging people to slow down and reflect.

This alternative form of consumption can be supported by an alternative conceptualization of marketing-Marketing as Societing. Badot et al. (1993) introduced this reformulation through the concept of societing which means either to 'put in the society' or 'to make society' (Badot and Cova, 1992, 2008). In societing, 'the company is not a simple economic actor who adapts to the market, but a social actor embedded in the societal context' (Badot et al. 1993, p. 51). The logic of 'marketing to' is replaced by the logic of 'marketing with' and in practice this may mean pricing to constrain rather than to stimulate sales. This would require targeted measures to avoid creating a regressive regime that would affect the poorest the most. Marketing 'with' would also include adapting legal frameworks to privilege socially-orientated companies and investment in sustainable production.

This approach invites both companies and citizens to consider collaborative consumption practices that promote exchange and the circulation of value among consumers. It attributes relevance to sharing and giving, and it highlights the significance of production created by consumers. Through collaborative and societal practices such as sharing, gifting, and prosumption, alternatives are provided to current forms of buying and ownership (Botsman and Rogers, 2010) whereby our relations with possessions become more liquid (Bardhi and Eckhardt, 2012) and increase feelings of solidarity (Botsman and Rogers, 2010).

We recommend that marketing educators embrace 'societing' as a central concept and set the goal of using the tools of marketing to help 'make society' (Badot and Cova, 1992). The different forms of consumption and marketing described have the potential to reduce negative impacts on the physical environment, society, and individuals. This paper now offers local and national policy interventions designed to provide some of the resources (physical and psychological space, time, skills) that could enable alternative hedonism and control current marketing practices to encourage marketing as societing.

\section{Controlling Marketing}


Policy makers have a range of levers including prohibition, tax incentives and procurement preferences that they can use to incentivize or dissuade certain behaviours. Overall, to control marketing, we believe that governments should take a more direct interventionist approach which includes banning practices rather than relying on self-regulation. However, in some ideas proposed in this section such as packaging design and material recovery use of this broader suite of options will be appropriate.

We support calls to control marketing (Harris et al., 2009; Schor, 2004) when it seeks to manipulate and encourage instead its use as a facilitator. We suggest that beyond a ban on the advertising of goods and services to children and other vulnerable groups that a complete ban on the targeting of these groups as consumers is required (this would include, for example, banning in-game advertising and sales offers widely used in computer games). Sponsorship arrangements between sporting, cultural and community groups and socially and personally damaging products like alcohol, gambling and high sugar drinks and should be mandated against. Control should also be enacted over the amount and size of advertising allowed in civic and shared spaces.

Where the self-regulation of advertising exists (such as in the United Kingdom and Australia) we recommend moving instead to a fully co-regulated system. This change should also include adding 'Does not undermine sense of personal or social self' as a key principle to which marketing communications must adhere.

Many of the other supported restrictions on marketing are to be found in the existing sustainability literature. In particular, ensuring lifecycle analysis and input/output assessments are performed and reported on products acts to create transparency for the consumer and restrict unethical practices by organisations. Hence we support material input labelling (Maxwell and Van der Vorst, 2003) and believe it should be mandated and include full information regarding the resources used to make a product and the waste products produced. If this takes up space on the packaging and reduces the area available for potentially misleading claims (Hajer and Wagenaar, 2003) and makes the product less attractive, then we consider this an additional benefit. Producers should be made legally responsible for end-of-life disposal and recovery of increasing percentages of materials across a range of durable goods (i.e. IT, cars, white 
goods, furniture). This will encourage design for the environment processes including design for disassembly (Arnette et al., 2014).

Packaging waste should be treated as a design flaw (Stahel, 2010) and accordingly it should be the producer's responsibility, not that of the consumer or the municipal council who currently deal with the rubbish it creates and the degradation of community spaces. To encourage packaging return, reuse, and re-manufacture, as is mandated in Germany (D P G, 2016), uniform bottle and container sizes should be introduced, as should container deposit legislation. Uniform sizes allow for simpler return and reuse as they do not have to be sorted by manufacturer and brand.

Local and national planning regulations should prioritize local and urban centres as places to live, work, play, congregate, and shop, giving priority to local, circular economies where local multiplier effects are seen in terms of economic and relationship benefits. The sales of individually and socially damaging goods should be banned from schools, libraries and other community-owned spaces. What constitutes a damaging 'good' could be determined by an independent organisation constituted to fulfill the principles of deliberative policy making so comprising of both 'experts' and citizens (Hajer and Wagenaar, 2003).

Prices must include the full cost of producing, maintaining and disposing of goods throughout their life cycles (Munksgaard et al., 2005). Crucially, this will involve fully accounting for the cost of the pollution created across these stages. This will go beyond just the cost of carbon emissions and include charges for pollution and environmental remediation work required to clean our land, air and water. Fresh impetus must be given to an international, GHG pollution cap and trading schemes. Bulk buy food deals should be restricted as they encourage faster and more mindless consumption and favour better off consumers with the resources to take advantage of these offers (Areni and Black, 2015).

\section{Creating Space for greater Participation}

Finally, as the previous ideas have helped create the intellectual space for different ideas and relationships with consumption, we also need to ensure there is the physical and temporal space to allow families and friends to express and participate in 
relationship-affirming, collective activities. This must include creating spaces that are physically, socially, culturally and psychologically safe and do not constrain by reinforcing gender roles nor favour those with monetary means. To increase participation where different forms of hedonic and participative experiences can be consumed, costs, accessibility, time and skills barriers must be addressed.

For example, for families with lower incomes, television represents one of the few affordable leisure activities when compared to participation in sporting, cultural or artistic activities, which often are associated with financial barriers to entry (such as entrance fees or the cost of equipment). It should be a goal of local and national government to ensure community participation should be cheaper than, or comparable to, participation in passive isolating activities such as watching television and the pro-consumption advertisements that pervade this medium.

\section{Conclusions}

This paper has outlined ideas for different forms of consumption and participation that may address the many negative environmental, social and personal impacts invidious materialism currently creates. By restricting the neoliberal narrative and by highlighting a different form of marketing to be taught and understood, it highlights how the tools and skills of this discipline can be put to work to build society and help develop and maintain affirming relationships, rather than driving individualism. These messages are then supported by governmental interventions designed to allow people psychological and physical space to explore these different ways of consuming and in particular to increase participation in society building activities.

\section{References}

Abelson, R.P., 1968. Theories of cognitive consistency: a sourcebook. Rand McNally College Publishing Company, Chicago, Illinois.

Areni, C.S., Black, I., 2015. Consumers' responses to small portions: Signaling increases savoring and satiation. Psychol. \& Marketing 32, 532-543. 
Arnette, A.N., Brewer, B.L., Choal, T., 2014. Design for sustainability (DFS): the intersection of supply chain and environment. J. Clean. Prod.. 83, 374-390.

Arnould, E.J., Thompson, C.J., 2005. Consumer culture theory (CCT): Twenty years of research. J. of Consum. Res. 31, 868-882.

Badot, O., Bucci, A., Cova, B., 1993. Societing: Managerial response to European aestheticization. Eur. Manag. J. Special Issue EAP 20th Anniversary, 48-55.

Badot, O., Cova, B., 1992. Le Néo-Marketing. Paris, ESF.

Badot, O., Cova, B., 2008. The myopia of new marketing panaceas: the case for rebuilding our discipline. J. of Marketing Manag. 24, 205-219.

Bardhi, F., Eckhardt, G.M., 2012. Access-based consumption: The case of car sharing. J. of Consumer Res. 39, 881-898.

Black, I.R., Cherrier, H., 2010. Anti-consumption as part of living a sustainable lifestyle: daily practices, contextual motivations and subjective values. J. of Consum. Behav. 9, 437-453.

Black, I.R., Shaw, D.S., Trebeck, K., 2015. Changing the narrative in Scotland's relationship with consumption. Common Weal, Biggar.

Botsman, R., Rogers, R., 2010. What's mine is yours. Collins, London.

Brown, C., 1997. Consumer credit and the propensity to consume: evidence from 1930. J. of Post Keynesian Economics 19, 617-638.

Bruner, J., 1991. The narrative construction of reality. Crit. Inq. 18, 1-21.

Centeno, M.A., Cohen, J.N., 2012. The arc of neoliberalism. Annu. Rev. of Socio. 38, 317-340.

Chartered Institute of Marketing, 2016. What is Marketing? http://www.cim.co.uk/more/getin2marketing/what-is-marketing/, Accessed 12/09/2016. Connolly, J., Prothero, A., 2003. Sustainable consumption: consumption, consumers and the commodity discourse. Consum., Mark. and Cult. 6, 275-291.

Csikszentmihalyi, M., 2000. The costs and benefits of consuming. J. of Consum. Res. 27, 267-272.

D P G, 2016. Compulsory deposit for drinks in on-way drinks packaging. 
Ellen, P.S., Wiener, J.L., Cobb-Walgren, C., 1991. The role of perceived consumer effectiveness in motivating environmentally conscious behaviors. J. of Public Policy \& Marketing, 102-117.

Ger, G., Belk, R.W., 1999. Accounting for materialism in four cultures. J. of Mater. Cult. 4, 183-204.

Hajer, M.A., Wagenaar, H., 2003. Deliberative policy analysis: understanding governance in the network society. Cambridge University Press.

Hardin, G., 2009. The Tragedy of the Commons. J. of Nat. Resour. Policy Res. 1, 243253.

Harris, J.L., Pomeranz, J.L., Lobstein, T., Brownell, K.D., 2009. A crisis in the marketplace: how food marketing contributes to childhood obesity and what can be done. Annu. Rev. of Public Health 30, 211-225.

Harvey, D., 2007. A brief history of neoliberalism. Oxford University Press, USA. Ivanova, M.N., 2011. Consumerism and the Crisis: Wither the 'American Dream'? Crit. Sociol. 37, 329-350

Jackson, T., 2011. Prosperity without growth: Economics for a finite planet. Routledge. Leary, R.B., Vann, R.J., Mittelstaedt, J.D., Murphy, P.E., Sherry, J.F., 2014. Changing the marketplace one behavior at a time: Perceived marketplace influence and sustainable consumption. J. of Bus. Res. 67, 1953-1958.

Maxwell, D., Van der Vorst, R., 2003. Developing sustainable products and services. J. Clean. Prod. 11, 883-895.

Munksgaard, J., Wier, M., Lenzen, M., Dey, C., 2005. Using Input-Output analysis to measure the environmental pressure of consumption at different spatial levels. J. of Ind. Ecol. 9, 169-185.

Page, C., 1992. A history of conspicuous consumption. SV-Meaning, Measure, and Morality of Materialism.

Prothero, A., McDonagh, P., Dobscha, S., 2010. Is green the new black? Reflections on a green commodity discourse. J. of Macromarketing 30, 147-159.

Schor, J., 2004. Born to buy: The commercialized child and the new consumer culture. Simon and Schuster, New York.

Scottish Government, 2016. Scottish Greenhouse Gas Emissions 2014. 
Shukla, P., 2008. Conspicuous consumption among middle age consumers:

psychological and brand antecedents. J. of Prod. \& Brand Manag. 17, 25-36.

Shultz, C.J., Holbrook, M.B., 1999. Marketing and the tragedy of the commons: A

synthesis, commentary, and analysis for action. J. of Public Policy \& Marketing, 218-

229.

Soper, K., 2005. Feminism and Enlightenment Legacies. Palgrave MacMillan, UK.

Soper, K., 2007. Rethinking the 'good life': The citizenship dimension of consumer

disaffection with consumerism. J. of Consum. Cult. 7, 205-229.

Soper, K., 2008. Alternative hedonism, cultural theory and the role of aesthetic revisioning. Cult. Stud. 22, 567-587.

Soper, K., 2009. Other pleasures: The attractions of post-consumerism. Social. Regist. $36,115-132$.

Soper, K., 2013. The dialectics of progress: Irish 'belatedness' and the politics of prosperity. Ephemera 13, 249-267.

Stahel, W.R., 2010. Managing Performance Over Time, The Performance Economy. Springer, pp. 179-268.

Stocker, T.F., 2014. Climate change 2013: the physical science basis: Working Group I contribution to the Fifth assessment report of the Intergovernmental Panel on Climate Change. Cambridge University Press.

Vicente-Molina, M.A., Fernández-Sáinz, A., Izagirre-Olaizola, J., 2013. Environmental knowledge and other variables affecting pro-environmental behaviour: comparison of university students from emerging and advanced countries. J. Clean. Prod. 61, 130-138. 